\title{
BMJ Open Gendered relationship between HIV stigma and HIV testing among men and women in Mozambique: a cross- sectional study to inform a stigma reduction and male-targeted HIV testing intervention
}

\author{
Judy $\mathrm{H} \mathrm{Ha},{ }^{1}$ Lynn M Van Lith, ${ }^{2}$ Elizabeth $\mathrm{C}$ Mallalieu, ${ }^{2}$ Jose Chidassicua, ${ }^{2}$ \\ Maria Dirce Pinho, ${ }^{2}$ Patrick Devos, ${ }^{2}$ Andrea L Wirtz ${ }^{3}$
}

To cite: Ha JH, Van Lith LM, Mallalieu EC, et al. Gendered relationship between HIV stigma and HIV testing among men and women in Mozambique: a cross-sectional study to inform a stigma reduction and male-targeted HIV testing intervention. BMJ Open 2019;9:e029748. doi:10.1136/ bmjopen-2019-029748

- Prepublication history and additional material for this paper are available online. To view these files, please visit the journal online (http://dx.doi. org/10.1136/bmjopen-2019029748).

Received 14 February 2019 Revised 03 June 2019 Accepted 04 September 2019

A Check for updates

(c) Author(s) (or their employer(s)) 2019. Re-use permitted under CC BY-NC. No commercial re-use. See rights and permissions. Published by BMJ.

For numbered affiliations see end of article.

Correspondence to

Andrea L Wirtz; awirtz1@jhu.edu

\section{ABSTRACT}

Objectives Increasing and sustaining engagement in HIV care for people living with HIV are critical to both individual therapeutic benefit and epidemic control. Men are less likely to test for HIV compared with women in sub-Saharan African countries, and ultimately have delayed entry to HIV care. Stigma is known to impede such engagement, placing an importance on understanding and addressing stigma to improve HIV testing and care outcomes. This study aimed to assess the gendered differences in the relationship between stigma and HIV testing.

Design and setting A cross-sectional, household probability survey was implemented between November and December 2016 in the Sofala province of Mozambique.

Participants Data were restricted to men and women participants who reported no prior diagnosis of HIV infection $(\mathrm{N}=2731)$.

Measures Measures of sociodemographic characteristics, stigma and past exposure to HIV interventions were included in gender-stratified logistic regression models to estimate the relationship between stigma and recent testing for HIV, as well as to identify other relevant correlates.

Results Significantly fewer men (38.3\%) than women (47.6\%; $p<0.001)$ had recently tested for HIV. Men who reported previous engagement in community group discussions about HIV had an increased odds of testing in the past 12 months compared to those who had not participated (adjusted OR $(\mathrm{aOR})=1.92 ; 95 \% \mathrm{Cl} 1.51$ to 2.44). Concerns about stigma were not a commonly reported barrier to HIV testing; however, men who expressed anticipated individual HIV stigma had a 35\% lower odds of recent HIV testing (aOR=0.65; $95 \% \mathrm{Cl}$ 0.44 to 0.96 ). This association was not observed among women.

Conclusions Men have lower uptake of HIV testing in Mozambique when compared to women. Even amidst the beneficial effects of HIV messaging, individual stigma is negatively associated with recent HIV testing among men. Intervention efforts that target the unique challenges

\section{Strengths and limitations of this study}

- This large, household probability survey explores the barriers to HIV testing, including stigma, which are distinct among men and women in a high HIV burden area district of Mozambique.

- HIV stigma was assessed using comprehensive measures to capture five relevant stigma domains: shame/blame/isolation, inequity, discrimination, perceived community stigma, and anticipated individual stigma towards people living with HIV.

- Stigma domains and other potential correlates of recent HIV testing were stratified by gender to provide evidence for strategies to improve HIV testing and care among men.

- As a cross-sectional analysis, temporality was not established.

and needs of men are essential in promoting men's engagement into the HIV care continuum in sub-Saharan Africa.

\section{INTRODUCTION}

Global efforts are underway to achieve the Joint United Nations Programme on HIV/ AIDS 2020 targets in which $90 \%$ of all people living with HIV (PLHIV) will know their HIV status, $90 \%$ of all people with diagnosed HIV infection will receive sustained antiretroviral therapy (ART), and $90 \%$ of all people receiving ART be virally suppressed (90-90-90 strategy). This strategy aims to change the epidemic trajectories in many countries through treatment as prevention. ${ }^{1}$ Despite the emphasis on the role of HIV testing in the HIV care continuum, challenges remain in achieving global targets by $2020{ }^{2}$ 
In sub-Saharan Africa, substantial investments have targeted and been successful in achieving high coverage of HIV testing among women in the context of antenatal care services and services to prevent mother-to-child transmission. ${ }^{34}$ However, fewer efforts have directly targeted HIV prevention, testing, and care for men, and those that do include men often succeed in reaching women with greater frequency than men. ${ }^{5}$ In sub-Saharan Africa, HIV testing rates tend to be lower among men than women, which is often coupled with late entry to HIV care, poor retention in care and ART adherence, and greater mortality rates among men on treatment compared to women. ${ }^{5}{ }^{6}$ These gender gaps indicate a need to shift attention towards addressing the unique barriers of HIV testing uptake among men and their engagement in HIV prevention and care continuums in sub-Saharan Africa.

Observational studies have provided evidence on the role of HIV stigma in HIV testing and care. ${ }^{78}$ Qualitative and quantitative research have demonstrated that HIV is often associated with death, despite treatment advances, and that shame and blame are frequently assigned to PLHIV. ${ }^{9}$ Perceived HIV stigma can induce feelings of fear that prevent individuals from learning their HIV status, entering HIV-related facilities, and engaging in HIV-related services due to unwanted, negative attention of being identified as living with HIV, and has been associated with a two-fold increased odds of late presentation for HIV care in low-resource settings. ${ }^{911}$ A global meta-analysis estimated that HIV stigma was associated with 32\% reduced odds of ART adherence, as well as worse outcomes related to depression, social support, and access to and usage of health and social services. ${ }^{12}$ Complementary meta-analysis of qualitative data revealed that HIV-related stigma compromised general psychological processes, such as adaptive coping and social support, which are critical determinants of participants' ability to overcome the structural and economic barriers associated with poverty in order to successfully engage in care and adhere to ART. ${ }^{8}$ Noted as a major barrier to HIV testing in sub-Saharan Africa, fear of HIV-related stigma is potentially exacerbated by low perceived HIV risk and financial concerns for the cost of HIV testing and care. ${ }^{13}$ As men are less likely to seek testing, a critical evaluation of the relationship between stigma and other factors on the uptake of HIV testing among men should be explored to inform HIV prevention and care continuum interventions.

As the fourth leading country in number of PLHIV, Mozambique has an estimated range of 1.6-2.1 million PLHIV. ${ }^{14}$ The country has an adult HIV prevalence of $13.2 \%$, with $34 \%$ aware of their HIV status. ${ }^{15}$ Data from the national AIDS Indicator Survey found that men had almost twice the odds of being unaware of their HIV status, compared to women, and regional data demonstrate increased risk of advanced HIV disease and severe immunosuppression at diagnosis, clinical loss to follow-up, and death among men who are living with HIV. ${ }^{16-18}$ Low awareness of one's status is likely attributable to low HIV testing rates; in 2015 , only $38 \%$ of men participating in the
Demographic Health Survey (DHS) reported any history of HIV testing and only $19 \%$ had been tested within the last 12 months, compared with $31 \%$ among women. ${ }^{15}$ HIV testing services have expanded substantially across the country over the last decade and, with improved access, geographic information systems data mapped to serial cross-sectional surveys among women have found that distance to HIV testing services is no longer a barrier to HIV testing at the regional level. ${ }^{19}$ As such structural barriers are minimised, additional research to understand lingering barriers to HIV testing - the first entry point to HIV prevention and care continua-is needed. Reports produced by the People Living with HIV Stigma Index suggest that HIV stigma is prevalent in Mozambique, and qualitative data from Mozambique highlight the potential impact of moral stigma-the perception that HIV is associated with immoral behaviours-on HIV testing. ${ }^{20}{ }^{21}$ Gender-based differences in the association between stigma and HIV testing have not formally been assessed, but are necessary to understand differential uptake of HIV testing and awareness of HIV status.

The aim of this analysis was to identify and assess the role of HIV stigma and other correlates for recent uptake of HIV testing among men and women in a high-burden province in Mozambique. This study was conducted as part of a baseline survey for a subsequent community-based stigma reduction and HIV care continuum intervention in Mozambique, which had a specific focus on improving HIV testing among men.

\section{METHODS}

\section{Study site and population}

As part of a larger evaluation of a community-based intervention, a baseline, cross-sectional survey was conducted from November to December 2016. Eligibility requirements for participation in the study included providing signed consent to participate, being aged 18 years or older, and living in participating districts of the Sofala province in Mozambique. Sofala province was selected for the community-based interventions as it is one of the most HIV-affected areas of Mozambique with an adult HIV prevalence of $16.3 \%$ as of the 2015 DHS. $^{15}$

Two districts in Sofala province, Nhamatanda and Dondo, each comprised four facility sites and their surrounding catchment areas per district, were selected for participation in the survey. Within Dondo district, the following sites were included: Canhandula, Dondo Sede, Mafambisse, and Macharote. Nhamatanda Sede, Nharuchonga, Tica, and Lamego were participating sites in Nhamatanda district. Sites were selected based on matching catchment area population size, with final selection based on security and availability of clinical data that was required for the parent study. Sampling in each site was proportional to population size and determined through household probability selection. In this process, a designated data collector would begin with a random start in their assigned location, then approach the door 
of every third house counted on each side of the street. Data collectors were required to interview only a family member of the same gender; if no head of household of the data collector's gender was available, the data collection staff would coordinate availability to ensure a staff member of the same gender could administer the interview. Each interviewer continued until they surveyed their quota of participants in each location. Prior to research implementation, the local research team briefed community leaders about the participant selection process and obtained approval and buy-in for the survey implementation within their communities.

The sample size was based on the parent study to assess the impact of a community-based intervention on community-level HIV stigma and HIV testing among men. We assumed $80 \%$ power to detect a conservative $5 \%$ difference in the change in stigma at alpha $<0.05$ between intervention and control, with an assumption of $20 \%$ loss to follow-up between baseline and endline. This produced a target sample of 1500 per intervention or control group $(\mathrm{N}=3000$ total). Given the other outcomes of interest related to improvements in HIV testing among men, men were oversampled to produce a sample that comprised two-thirds men and one-third women. Considering the estimated sample size of 1500 per group, $66 \%$ of whom would be men and $20 \%$ loss to follow-up, it was estimated that there would be over $80 \%$ power to detect at least $10 \%$ difference in self-reported HIV testing among surveyed men in the intervention and control sites. A total of 3017 enrolled in the baseline survey; however, individuals who had self-reported living with HIV at the time of survey were excluded from this analysis, producing an effective sample size of $\mathrm{N}=2731$ for this analysis $(\mathrm{n}=1887$ men and $\mathrm{n}=844$ women).

\section{Measures}

Data for the baseline survey were collected through a tablet-based questionnaire administered by local interviewers. Interviewers were fluent in local languages of Sena or Ndao as well as Portuguese, had prior experience in health research, and had been trained on human subject protection and confidentiality. Survey administration took approximately 45 minutes. The socio-behavioural survey collected information on demographic characteristics including gender identity, exposure to HIV prevention and testing, knowledge of HIV, relationships with PLHIV, and a comprehensive set of HIV stigma measures.

To ascertain recent HIV testing (last 12 months), participants were asked if they had ever been tested for HIV within their lifetime. Those who responded positively and who had not reported a positive diagnosis on their last HIV test were then asked a categorical question of when their last HIV test was completed. This categorical response was then reclassified to a binary response to whether they had been tested within the last 12 months. Participants who reported no recent HIV testing were additionally asked to report reasons why they had not tested and could select multiple responses from a list of 13 potential barriers to testing.

HIV stigma was assessed using several measures to capture five relevant stigma domains. The HIV stigma scale developed by Genberg and colleagues in the sub-Saharan setting was used to measure feelings and perceptions about PLHIV and included three subscales measuring shame/blame/isolation, discrimination, and inequity of PLHIV (alpha: 0.79). ${ }^{22}$ The domain of shame gauged the participants' tendency to blame and disgrace PLHIV, discrimination captured the extent to which participants believe PLHIV are unfairly treated, and inequity encompassed the preconceived opinions and prejudice towards PLHIV. $^{22}$ An example statement from the discrimination subscale includes 'People living with HIV/AIDS face neglect from their families.' While this scale was originally conceptualised as a way to identify individual discrimination, the framing of the discrimination statements leaves it open to participant interpretation of whether this is the participant's own anticipated behaviours or the anticipated behaviours of others.

We developed new measures (seven items) to assess perceived HIV stigma within the community (alpha: $0.77)$. An example statement in this measure included, 'In this community, men who are known to be living with HIV have the same level of importance in society as men who are not living with HIV.' These sets of measures used 4-point Likert scale response options, in which 1 represented strong disagreement and 4 represented strong agreement with the statement. To score the community stigma measures and the HIV stigma scale, which comprised the three subscales, points from the Likert scale were summed across all items in the same measure, with the exception of those that were reverse coded, producing possible ranges in scores from 7 to 28 for perceived community stigma, 10 to 33 for shame/blame/isolation, 8 to 27 for discrimination, and 5 to 19 for inequity. A higher score meant greater levels of HIV stigma.

Measures of anticipated individual stigma towards PLHIV that are traditionally included in DHS AIDS Indicators Survey (five items) were also included in the survey to explicitly measure the individual participant's anticipated stigmatising behaviours towards PLHIV. An example question under the domain of anticipated individual HIV stigma asked, 'If you found out that one of your friends was living with HIV, would you still be friends with him/her? ${ }^{23}$ A total of five items were evaluated with dichotomous responses of yes or no and were ultimately combined into a single binary variable 'any anticipated individual stigma,' which is based on whether a participant endorses at least one of the five pertinent items. Online supplementary appendix displays the full set of stigma measures included in the survey.

\section{Statistical analyses}

This analysis aimed to identify the correlates of HIV testing among HIV-uninfected individuals in Mozambique and to evaluate whether gender modified the 
relationship between stigma, other variables of interest, and the outcome of recent HIV testing. Descriptive analysis that was stratified by gender was conducted to assess characteristics of the study sample, including prevalence of recent HIV testing and stigma scores. $\chi^{2}$ tests were implemented to assess differences by gender for categorical variables; t-tests were implemented to assess differences across continuous variables.

A bivariate analysis was initially performed to identify potential correlates of recent HIV testing among the total sample. Additional models were stratified by gender to determine variables that would be appropriate to include in the final model for each gender. The independent variables tested in the models included HIV prevention experience, HIV knowledge, and stigma among participants, while demographics, such as age and education level, were considered as potential confounders in the model. The five domains of stigma were tested separately in the models: scores for shame/blame/isolation, discrimination, and inequity subscales, as well as perceived community stigma, were tested as continuous variables, while anticipated individual stigma was tested as a binary variable.

Using variables identified in the bivariate models based on $\mathrm{p}<0.10$, a final multivariate logistic regression model was built to present adjusted ORs (aOR), which allowed for the controlling of potential confounders in the analysis. The logistic regression model was stratified by gender to present potential associations that differed between men and women for having recently tested for HIV.
Multivariable models were run for the combined sample, as well as separately for each gender. Of the variables that presented a difference in relationship by gender, interaction terms were added in the combined multivariate model to evaluate their statistical significance. Variance inflation factor was calculated to test for collinearity in the final models. The Hosmer-Lemeshow test was also conducted to test for goodness of fit. All analyses were conducted in STATA V.14 and adjusted for potential clustering of participants induced by the sampling methodology using complex survey design procedures. ${ }^{24}$

\section{Patient and public involvement}

No patients were involved in this study. As a cross-sectional household survey, the public were involved in community information sharing sessions before and after the study to support recruitment and sharing of study results, respectively. Members of the public were selected for participation in the survey via probability-based sampling. Results of the study have been shared with development agencies supporting HIV programming in Mozambique.

\section{RESULTS}

Table 1 provides a description of demographic characteristics by the gender of participants (no participants identified as transgender or gender non-binary). Men and women participants were similar in age, education, and income level. However, among the 2731 self-reported HIV-uninfected individuals (1887 men and 844 women),

\begin{tabular}{|c|c|c|c|c|}
\hline & Total $(\mathrm{N}=\mathbf{2 7 3 1 )}$ & Men $(n=1887)$ & Women $(n=844)$ & $p$-Value \\
\hline Age (SD), years & $35.5(15.5)$ & $37.3(16.2)$ & $31.6(12.8)$ & $<0.001$ \\
\hline $\begin{array}{l}\text { Average monthly income (SD), } \\
\text { MZN }\end{array}$ & $10700(380000)$ & $14221(460000)$ & $2944(4500)$ & 0.480 \\
\hline \multicolumn{5}{|l|}{ District of residence } \\
\hline Nhamatanda & $1385(50.7 \%)$ & $951(50.4 \%)$ & $434(51.4 \%)$ & 0.621 \\
\hline Dondo & $1346(49.3 \%)$ & $936(49.6 \%)$ & $410(48.6 \%)$ & \\
\hline \multicolumn{5}{|c|}{ Highest level of education completed } \\
\hline None or primary & $1396(56.5 \%)$ & $1004(55.6 \%)$ & $392(59.0 \%)$ & 0.087 \\
\hline Secondary & 1004 (40.6\%) & $744(41.2 \%)$ & $260(39.2 \%)$ & \\
\hline Technical school or university & $70(2.8 \%)$ & $58(3.2 \%)$ & $12(1.8 \%)$ & \\
\hline \multicolumn{5}{|l|}{ Current employment status } \\
\hline Unemployed & $1031(37.8 \%)$ & $532(28.2 \%)$ & $499(59.1 \%)$ & $<0.001$ \\
\hline Employed & $1699(62.2 \%)$ & $1354(71.8 \%)$ & $345(40.9 \%)$ & \\
\hline \multicolumn{5}{|l|}{ Marital status } \\
\hline Never married & $560(20.5 \%)$ & $456(24.2 \%)$ & $105(12.3 \%)$ & $<0.001$ \\
\hline Married & $1931(70.7 \%)$ & $1334(70.6 \%)$ & $598(70.9 \%)$ & \\
\hline Separated & $240(8.8 \%)$ & $98(5.2 \%)$ & $143(16.8 \%)$ & \\
\hline Mean number of children (SD) & $4(5)$ & $4(6)$ & $4(2)$ & \\
\hline
\end{tabular}

MZN, Mozambican metical. 
Table 2 Exposure to HIV interventions and HIV stigma among men and women in Sofala province, Mozambique

\begin{tabular}{|c|c|c|c|c|}
\hline & Total $(\mathrm{N}=\mathbf{2 7 3 1})$ & Men $(n=1887)$ & Women $(n=844)$ & $p$-Value \\
\hline \multicolumn{5}{|l|}{ HIV testing and exposure to HIV information } \\
\hline \multicolumn{5}{|l|}{ Tested in the last 12 months } \\
\hline No & $1602(58.8 \%)$ & $1161(61.7 \%)$ & $441(52.4 \%)$ & $<0.001$ \\
\hline Yes & $1121(41.2 \%)$ & $721(38.3 \%)$ & $400(47.6 \%)$ & \\
\hline \multicolumn{5}{|l|}{ Ever tested (lifetime) } \\
\hline No & $807(29.6 \%)$ & $670(35.6 \%)$ & $137(16.3 \%)$ & $<0.001$ \\
\hline Yes & 1919 (70.4\%) & $1214(64.4 \%)$ & $705(83.7 \%)$ & \\
\hline \multicolumn{5}{|l|}{ Know of an HIV testing centre } \\
\hline No & $156(5.7 \%)$ & $130(6.9 \%)$ & $26(3.1 \%)$ & $<0.001$ \\
\hline Yes & $2572(94.3 \%)$ & $1755(93.1 \%)$ & $817(96.9 \%)$ & \\
\hline \multicolumn{5}{|l|}{ Seen or read HIV informational fliers } \\
\hline No & $993(36.4 \%)$ & $546(29.0 \%)$ & $447(53.1 \%)$ & $<0.001$ \\
\hline Yes & $1733(63.6 \%)$ & $1338(71.0 \%)$ & $395(46.9 \%)$ & \\
\hline \multicolumn{5}{|l|}{ Heard any HIV discussion on the radio } \\
\hline No & $704(25.8 \%)$ & $378(20.1 \%)$ & $326(38.7 \%)$ & $<0.001$ \\
\hline Yes & $2022(74.2 \%)$ & $1506(79.9 \%)$ & $518(61.3 \%)$ & \\
\hline \multicolumn{5}{|l|}{$\begin{array}{l}\text { Participated in HIV community discussion } \\
\text { groups }\end{array}$} \\
\hline No & $2023(74.2 \%)$ & $1294(68.7 \%)$ & $729(86.5 \%)$ & $<0.001$ \\
\hline Yes & $704(25.8 \%)$ & $590(31.3 \%)$ & $114(13.5 \%)$ & \\
\hline $\begin{array}{l}\text { Median number of people known to be living } \\
\text { with HIV infection (IQR) }\end{array}$ & $1(0-5)$ & $1(0-4)$ & $1(0-4)$ & 0.005 \\
\hline \multicolumn{5}{|l|}{ HIV stigma measures } \\
\hline HIV shame subscale $(\mathrm{SD})^{\star}$ & $16.8(3.9)$ & $16.7(3.8)$ & $17.0(4.1)$ & 0.044 \\
\hline Discrimination of PLHIV subscale (SD)* & $16.1(3.4)$ & $16.1(3.5)$ & $16.3(3.2)$ & 0.080 \\
\hline Inequity for PLHIV subscale (SD)* & $8.6(2.4)$ & $8.3(2.2)$ & $9.2(2.5)$ & $<0.001$ \\
\hline Perceived community stigma of PLHIV (SD)* & $19.8(3.7)$ & $19.6(3.4)$ & $20.2(4.1)$ & $<0.001$ \\
\hline \multicolumn{5}{|l|}{ Any anticipated individual stigma towards PLHIV } \\
\hline No & $2336(86.2 \%)$ & $1636(87.3 \%)$ & $700(83.7 \%)$ & 0.013 \\
\hline Yes & $374(13.8 \%)$ & $238(12.7 \%)$ & $136(16.3 \%)$ & \\
\hline
\end{tabular}

*Scores of stigma subscales ranged from 10 to 33 for shame, 8 to 27 for discrimination, 5 to 19 for inequity, and 7 to 28 for community stigma.

PLHIV, people living with HIV.

men tended to have slightly higher levels of employment than women (table 1).

Table 2 describes participants' exposure to HIV testing, prevention resources, and perceptions of HIV stigma. More than half of the participants did not test for HIV in the year prior to the baseline survey, which was significantly higher among men $(61.7 \%$ vs $52.4 \%, \mathrm{p}<0.001)$. Women were more likely than men to have had a recent HIV test, while men were more commonly exposed to HIV information than women via the radio, informational fliers, and community discussion groups $(\mathrm{p}<0.001)$. With respect to the domains of stigma, participants had generally low levels of perceived stigma including shame/ blame/isolation, discrimination, or inequity towards PLHIV. Women were more likely than men to endorse at least one form of anticipated individual stigma towards PLHIV ( $16.3 \%$ vs $12.7 \%, \mathrm{p}=0.013)$ and reported higher on average scores than men in having perceived shame/ blame/isolation, feelings of inequity, and perceived community stigma towards PLHIV (table 2).

When asked to report the reasons for not having tested for HIV in the last 12 months, over half of participants who reported no recent test indicated it was because they felt healthy $(55 \%)$, lacked time for HIV testing (26\%), and had low perceived risk (21\%). Men were more likely to report feeling healthy and not having time to get tested than women. In a separate analysis, men who were currently employed were more likely to report lack of time as a barrier to HIV testing (ref: unemployed; OR=1.46; 95\% CI 1.09 to $1.95, \mathrm{p}=0.010$; data not displayed). Figure 1 


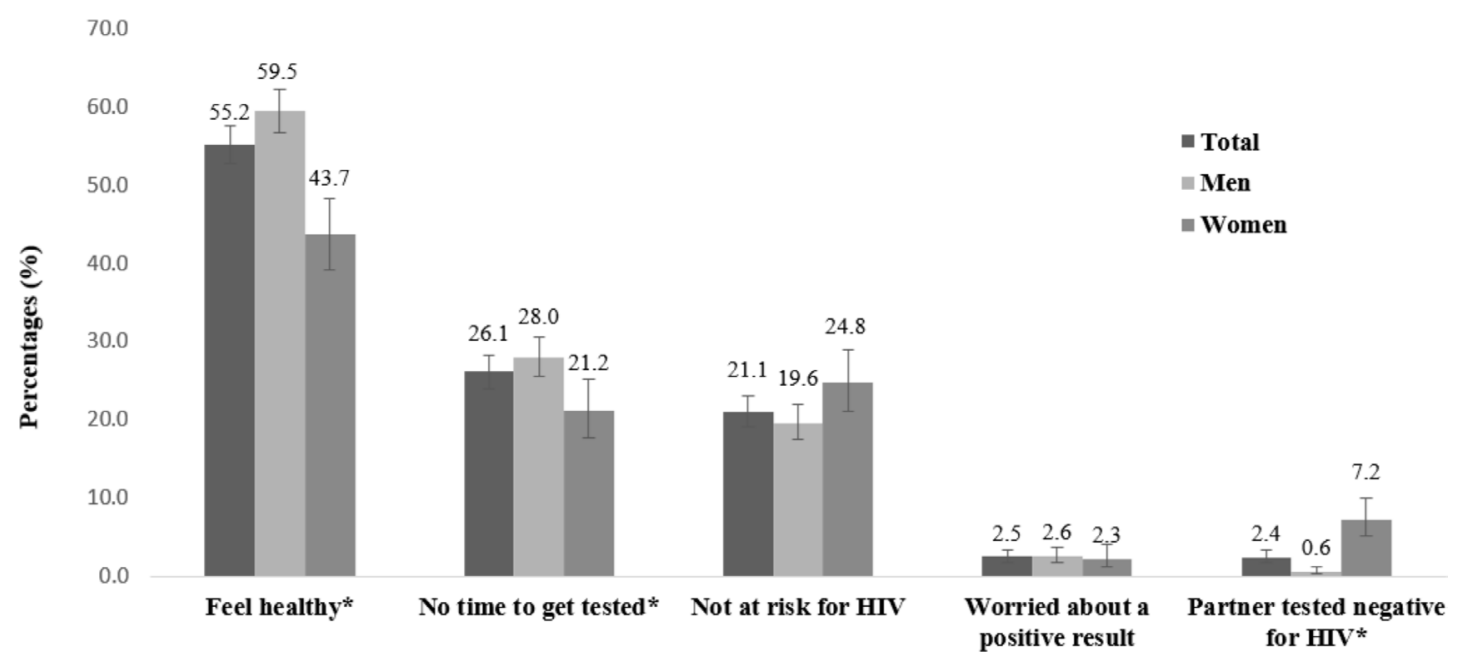

Figure 1 Five most common reasons for failing to test for HIV in the last 12 months among men and women in Sofala province, Mozambique. Note: ${ }^{*}$ indicates statistical significance at $\mathrm{p}<0.05$. Error bars represent $95 \% \mathrm{Cl}$.

displays the five most common reasons for failure to test among men and women. Concerns related to stigma and perceived gender norms associated with HIV testing were not commonly reported reasons for lack of recent HIV testing. For example, $1.7 \%$ of participants reported that they had not recently tested for HIV due to concerns about negative treatment by healthcare workers, as well as concerns that neighbours or families suspect that they are living with HIV infection $(0.4 \%)$, or concerns that people would believe they were unfaithful or misbehaving $(0.5 \%)$.

In the multivariable logistic regression model that included the combined sample of men and women (table 3), the odds of recent HIV testing were almost two times higher among women than men $(\mathrm{aOR}=1.79 ; 95 \%$ CI 1.39 to 2.30). Other correlates of recent HIV testing included being married, attaining secondary education or technical school or university, past receipt of informational fliers about HIV, knowing two or more people who were living with HIV, and past participation in community group discussions about HIV were also significantly associated with recent HIV testing. Modest associations were observed among all male and female participants in terms of anticipated individual stigma and inequity for PLHIV; participants who endorsed at least one form of anticipated individual stigma towards PLHIV had a $26 \%$ reduced odds of recent HIV testing, compared to those with none $(\mathrm{aOR}=0.74 ; 95 \% \mathrm{CI} 0.54$ to 1.01$)$. The subscale measuring feelings of inequity for PLHIV had a modest positive association with HIV stigma, wherein for each point higher on the scale, there was a 1.07 increased odds in recent HIV testing ( $\mathrm{aOR}=1.07 ; 95 \%$ CI 1.02 to 1.13 ).

To explore the effect modification by gender in the relationship between stigma and recent HIV testing and to identify unique correlates of recent HIV testing, gender disaggregated multivariable logistic regression models were implemented (table 4). Among men, higher education, knowing two or more people who were living with HIV ( $\mathrm{aOR}=1.38 ; 95 \%$ CI 1.08 to 1.76 ), and engagement in community discussion groups $(\mathrm{aOR}=1.92 ; 95 \%$ CI 1.51 to 2.44) were associated with increased odds of recent HIV testing. Men who endorsed at least one form of anticipated individual stigma towards PLHIV had a 35\% lower odds of recent HIV testing $(\mathrm{aOR}=0.65 ; 95 \%$ CI 0.44 to 0.96 ), whereas there was a modest positive association between the inequity subscale and HIV testing among men $(\mathrm{aOR}=1.10 ; 95 \%$ CI 1.03 to 1.17$)$.

Women with secondary education and who were currently married were more likely to report recent HIV testing. Having seen or read any informational fliers about HIV was also associated with an increased odds of recent HIV testing among women $(\mathrm{aOR}=1.83 ; 95 \%$ CI 1.25 to 2.66$)$.

\section{DISCUSSION}

Stigma has a well-documented role in inhibiting engagement across the HIV prevention and care continuums, and greater understanding, particularly for men who are less engaged in the HIV care continuum, is critical to meeting global epidemic targets. ${ }^{25}$ This study found that endorsement of anticipated individual stigma among men was associated with a $35 \%$ reduced odds of recent HIV testing-a finding that was unique to men. The measures of anticipated individual stigma captured how participants felt they would personally react to PLHIV; given the magnitude of the association among men, this suggests that men may avoid HIV testing to avoid similar treatment by others. Conversely, exposure to HIV informational messages through community discussions and fliers was positively associated with recent HIV testing for men, as well as for women. These findings suggest that interventions to improve HIV testing for men may be optimised by providing both stigma reduction efforts as well as communication about the benefits and importance of HIV testing.

While anticipated individual HIV stigma was found to be associated with decreased odds of recent HIV testing 
Table 3 Correlates of recent HIV testing (last 12 months) among all participants ( $N=2332$ )

\begin{tabular}{|c|c|c|c|c|}
\hline \multirow[b]{2}{*}{ Variable } & \multicolumn{2}{|l|}{ Crude } & \multicolumn{2}{|l|}{ Adjusted } \\
\hline & OR (95\% Cl) & $p$-Value & Adj. OR (95\% Cl) & $p$-Value \\
\hline \multicolumn{5}{|l|}{ Demographic characteristics } \\
\hline Women (Ref: men) & 1.46 (1.24 to 1.72$)$ & $<0.001$ & 1.79 (1.39 to 2.30$)$ & $<0.001$ \\
\hline Age & 0.98 (0.98 to 0.99$)$ & $<0.001$ & 0.98 (0.98 to 0.99$)$ & $<0.001$ \\
\hline \multicolumn{5}{|l|}{$\begin{array}{l}\text { Highest level of education completed (Ref: none or } \\
\text { primary) }\end{array}$} \\
\hline Secondary & 1.75 (1.48 to 2.07$)$ & $<0.001$ & 1.48 (1.20 to 1.82$)$ & $<0.001$ \\
\hline Technical school or university & 4.79 (2.80 to 8.20$)$ & $<0.001$ & 3.66 (1.96 to 6.86$)$ & $<0.001$ \\
\hline Currently employed (Ref: unemployed) & $1.11(0.95$ to 1.30$)$ & 0.194 & $1.06(0.85$ to 1.31$)$ & 0.610 \\
\hline \multicolumn{5}{|l|}{ Marital status (Ref: never married) } \\
\hline Married & $1.10(0.90$ to 1.33$)$ & 0.350 & 1.71 (1.31 to 2.21$)$ & $<0.001$ \\
\hline Separated & 0.75 (0.55 to 1.04$)$ & 0.082 & 1.19 (0.75 to 1.89$)$ & 0.466 \\
\hline \multicolumn{5}{|l|}{$\begin{array}{l}\text { Number of people participant knows who are living } \\
\text { with HIV (Ref: none) }\end{array}$} \\
\hline One & 1.15 (0.86 to 1.53$)$ & 0.357 & $1.22(0.88$ to 1.70$)$ & 0.228 \\
\hline Two or more & 1.65 (1.39 to 1.97$)$ & $<0.001$ & 1.37 (1.11 to 1.68$)$ & 0.003 \\
\hline \multicolumn{5}{|l|}{ HIV testing and exposure to HIV information } \\
\hline Seen or read HIV informational fliers & $1.83(1.56$ to 2.16$)$ & $<0.001$ & $1.71(1.32$ to 2.17$)$ & $<0.001$ \\
\hline Heard any HIV discussion on the radio & 1.14 (0.96 to 1.36$)$ & 0.144 & $0.93(0.73$ to 1.17$)$ & 0.531 \\
\hline Participated in HIV community discussion groups & $1.78(1.50$ to 2.12$)$ & $<0.001$ & 1.75 (1.41 to 2.18$)$ & $<0.001$ \\
\hline \multicolumn{5}{|l|}{ HIV stigma measures } \\
\hline HIV shame subscale & 0.96 (0.94 to 0.98$)$ & $<0.001$ & 0.98 (0.95 to 1.01$)$ & 0.158 \\
\hline Discrimination of PLHIV subscale & $0.98(0.96$ to 1.00$)$ & 0.081 & 0.99 (0.96 to 1.02$)$ & 0.534 \\
\hline Inequity for PLHIV subscale & $1.00(0.97$ to 1.04$)$ & 0.783 & 1.07 (1.02 to 1.13$)$ & 0.005 \\
\hline Perceived community stigma of PLHIV & $1.04(1.01$ to 1.06$)$ & 0.002 & 1.02 (0.99 to 1.05$)$ & 0.162 \\
\hline $\begin{array}{l}\text { Any anticipated individual stigma towards PLHIV (Ref: } \\
\text { no) }\end{array}$ & $0.51(0.40$ to 0.65$)$ & $<0.001$ & $0.74(0.54$ to 1.01$)$ & 0.056 \\
\hline
\end{tabular}

PLHIV, people living with HIV.

among men, concerns related to HIV stigma were not often a reported reason for not completing HIV testing within the last 12 months. Rather, participants predominantly reported that they did not seek testing because they felt they were not at risk for HIV, felt healthy, or did not have time. There are two (not mutually exclusive) potential explanations for these disparities in findings. Within social epidemiology, stigma is widely viewed and measured as a latent trait, as it was in this analysis that used comprehensive scales to measure various forms of HIV stigma. ${ }^{22} 23$ Thus, specific concerns related to stigma as a reason for failing to test for HIV may be very different in perceived significance from what may be captured by more comprehensive scales that capture the multitude manifestations of HIV stigma. Second, it is possible that stigma serves as an overarching issue that impacts individual efforts to overcome barriers to HIV testing, as suggested by other authors. ${ }^{8}$ In this sense, stigma that is present ubiquitously among individuals may prevent them from resolving more immediate barriers related to time or perceived risk for HIV acquisition. Addressing both immediate barriers to HIV testing as well as reducing stigma are important areas of focus for HIV testing interventions for men, who do not have the same normative access to HIV testing that women do through antenatal programmes.

Unlike the relationships identified for men, we found that women endorsed greater feelings of stigma towards PLHIV compared with men; however, stigma did not appear to be associated with women's testing behaviours. One likely explanation for the gender differential in recent HIV testing and the lack of correlation with stigma among women is the availability of HIV testing in routine antenatal care. Other research from Sofala province estimated that at least $74 \%$ of women routinely receiving antenatal care services in the Sofala province had tested for HIV in 2009-an estimate that has likely increased in recent years. ${ }^{26}$ It may be that, unlike for men, antenatal care services allow women to access HIV testing within the context of other reproductive care. With women visiting health facilities for antenatal care, following and providing regular HIV prevention and care services, among other services, is more common for women than 
Table 4 Adjusted associations with testing for HIV in the last 12 months by gender

\begin{tabular}{|c|c|c|c|c|}
\hline \multirow[b]{2}{*}{ Variable } & \multicolumn{2}{|l|}{ Men $(n=1714)$} & \multicolumn{2}{|l|}{ Women $(n=618)$} \\
\hline & Adj. OR (95\% Cl) & $p$-Value & Adj. OR (95\% Cl) & $p$-Value \\
\hline \multicolumn{5}{|l|}{ Demographic characteristics } \\
\hline \multicolumn{5}{|c|}{$\begin{array}{l}\text { Highest level of education completed (Ref: none or } \\
\text { primary) }\end{array}$} \\
\hline Currently employed (Ref: unemployed) & $1.06(0.83$ to 1.36$)$ & 0.689 & $1.09(0.75$ to 1.56$)$ & 0.638 \\
\hline \multicolumn{5}{|l|}{ Marital status (Ref: never married) } \\
\hline Married & 1.60 (1.17 to 2.19$)$ & 0.003 & 2.01 (1.21 to 3.34$)$ & 0.007 \\
\hline Separated & $1.10(0.57$ to 2.11$)$ & 0.773 & 1.55 (0.74 to 3.27$)$ & 0.245 \\
\hline
\end{tabular}

Number of people participant knows who are living with HIV (Ref: none)

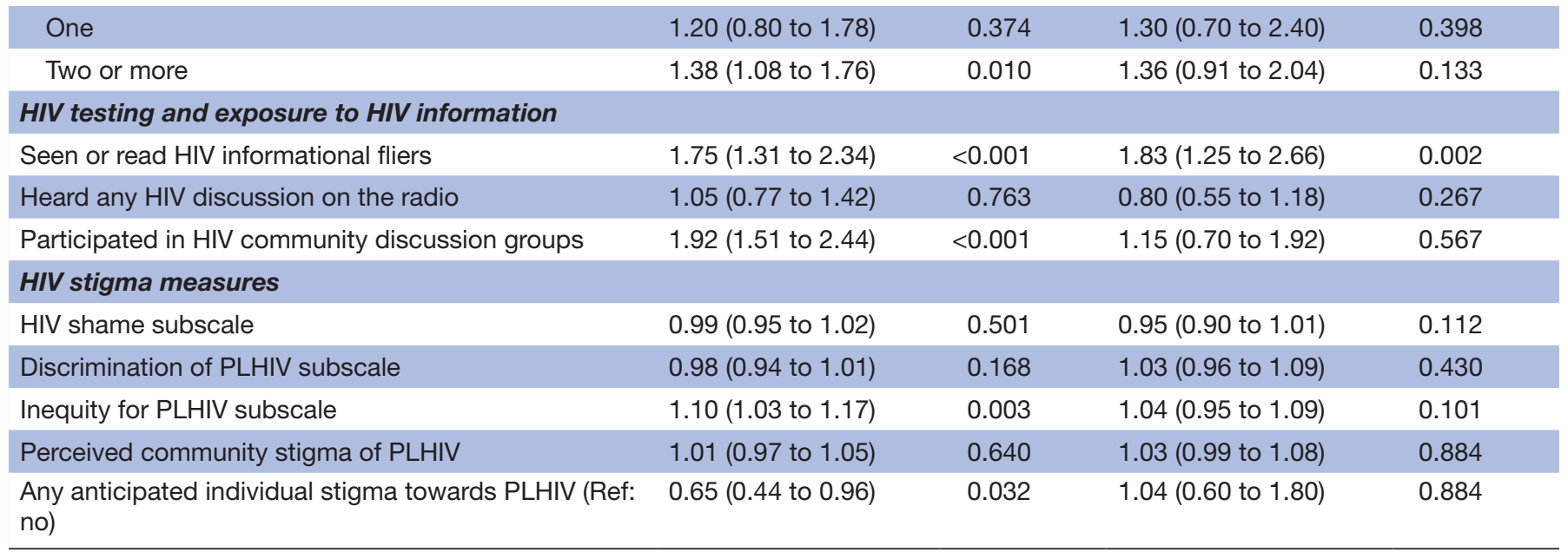

PLHIV, people living with HIV.

for men. ${ }^{27}$ In theory, male partners may access HIV testing at antenatal care sites through their partner; however, in practice, men's engagement in antenatal care services is low in Mozambique. ${ }^{28}$ Given that specialty services for men are not common within health facilities, increasing testing opportunities in locations that men frequent, such as hosting workplace testing events, and providing selftesting services at home or within the community are strategies to improve HIV testing among men. ${ }^{29}$ These testing interventions may reduce barriers associated with anticipated HIV stigma, as well as observed barriers related to time constraints and perceptions of being healthy.

Community discussion groups were found to be positively associated with recent HIV testing in this study and have previously been successful in influencing a change in gender attitudes, gender roles, and HIV stigma that also play a part in the uptake of HIV prevention and care services. ${ }^{30}$ Considering the higher proportion of men than women exposed to HIV prevention messages, increasing and effectively distributing HIV prevention resources that deliver information on HIV via fliers and community discussion groups among others are important for future interventions targeting men. Contrary to these findings, an association was not observed between hearing discussions about HIV on the radio and recent HIV testing. The content of the radio programmes that participants had heard was not documented and it may be the case that some radio programmes contained negative messages or misinformation. A closer evaluation of the content of the radio programmes would allow for better understanding of its relationship with recent testing for HIV. As radio is one of the most dominant forms of communication within Mozambique, with over $90 \%$ of households reportedly owning a radio, developing positive messages for radio dissemination may play an important role in encouraging HIV testing and reducing misinformation and stigma. ${ }^{31}$

Finally, knowing multiple individuals who are living with HIV was positively associated with recent HIV testing among men. In this case, witnessing the benefits of testing and prompt ART initiation may buffer against stigma and motivate men to initiate or increase the frequency of HIV testing. These findings are consistent with other prospective research conducted in South Africa, which demonstrated that knowing others who were living with HIV 
decreased individual stigma of HIV over time, and ultimately increased uptake of community voluntary counselling and testing. ${ }^{32}$

The findings should be viewed in light of study limitations. With the exception of the perceived community stigma measures, other stigma measures were established a decade ago and items may need to be added or adjusted to account for changing social dynamics and programming as the epidemic progresses. The community stigma measure was developed for the purpose of this assessment and has not been validated, though psychometric testing is underway. As a cross-sectional analysis, temporality was not established and the direction of the associations cannot be established. Given that stigma takes long periods of time to develop and change, we presume that stigma influences recent HIV testing behaviours; however, there is the possibility that HIV testing experiences could have changed participants' perspectives about stigma. Further, there is the possibility that greater HIV stigma may increase HIV testing as a means to prevent the disease, as may be the case for women who endorsed greater stigma. Such a relationship has not been borne out in the scientific literature. The observation that current marriage is one of the strongest correlates of recent HIV testing among women, likely because it is also correlated with number of child births, rather suggests that the effects of stigma may be overcome by routine HIV testing in the context of prenatal care for women. Finally, social desirability bias could have influenced our estimates of stigma and HIV testing.

\section{CONCLUSION}

Stigma is and should be widely recognised as a potent social determinant in health-seeking behaviours that compromises health among populations, particularly as it relates to HIV testing and care. ${ }^{33}$ Of the various forms of stigma, anticipated individual stigma was found to be strongly associated with reduced uptake of recent HIV testing among men. The availability of HIV testing within antenatal care services provides opportunities for women to engage in HIV testing, while challenges to engage men in HIV testing and, broadly, the HIV care continuum persist. Findings from this study suggest that efforts to improve HIV testing among men should focus on addressing both stigma reduction and immediate barriers to HIV testing, and may be able to build on the positive effects of community-based HIV prevention and care activities. As HIV testing and diagnosis are essential to linking individuals to treatment and care, acting on the individual, social and structural barriers that disparately impact men and women will be necessary to achieving the ambitious goal of 90-90-90 to end the HIV epidemic in sub-Saharan Africa.

\section{Author affiliations}

${ }^{1}$ Department of Epidemiology, Johns Hopkins Bloomberg School of Public Health, Baltimore, Maryland, USA
2Johns Hopkins University Center for Communication Programs, Baltimore, Maryland, USA

${ }^{3}$ Center for Public Health and Human Rights, Department of Epidemiology, Johns Hopkins Bloomberg School of Public Health, Baltimore, Maryland, USA

Acknowledgements The authors express their gratitude to the many participants of this research; this work would not be possible without their participation and experiences. Further, this intervention and evaluation would not be possible without the diligent efforts of an enormous team of people. We thank USAID for their support of the intervention, without which Sawa would not have been implemented. We acknowledge the participation and lived experiences of the community members and leaders in the Dondo and Nhamatanda communities. The following people are acknowledged for their contribution to the implementation of Sawa and the evaluation: Kim Ahanda (USAID), Lopa Basu (USAID), Shadit Murargy (USAID), Julio Machava (USAID) and Ferreira Ferreira (USAID); Matilde Cunhaque (CCP Maputo); Johns Hopkins University research assistants Jackie Tran, Shirley Yan and Bee-Ah Kang; Survey data collectors in Nhamatanda: Armando Bandazi Castigo, Burcela Domingos Cofereme, Creva Bernardo Nharuchonga, Joao Francisco Jo, Fabiao Muchanga, France Licete Agostinho Tete, Jose Fernando Jose, Daniel Moiane Jossias, Rui Vasco Araujo, Salmo Joao Jaquecene, Manuel Francisco Comissal, Domingos Lubico Marrove, Nelson Nunes Nicoadala, Carlota Elisa Massora, Celeste Massasse Ferrao Vilanculo, Claudia Luisa Manuel Macamo, Helena Elias Mastala and Claudina Lourenco dos Santos Chival; Survey data collectors in Dondo: António Adelino Tembo, Daniel Arone, Fernando Chafinhe, Joaquim Joao Jone, Nelson Araujo de Jesus, Pedro Joao Jemuce, Pedro Maria Alves, Simoes Antonio Mussa, Domingos Joao Muanda, Noe Joao Guiane, Rita Zacaria Vicentes, Casimira Cossa Domingos Manuel, Lurdes Guente Licova, Muaziza Abudo, Olga Miquelina Francisco, Loyd Mimi Nsona, Carolina Rui Vasco Araujo Dembuenda and Maria do Ceu Baute Cunhaque; Field supervisors: Etelvino Ernesto Sande, Aleixo Francisco Dembuenda, Brigida Nhantumbo and Natercia Carolina Sousa Manuel; Sergio João Maondera; and Nancy Perrin at Johns Hopkins who provided statistical input.

Contributors LMVL, ECM, PD and ALW designed the study concept. JC and DP oversaw data collection. ALW, JHH and JC had full access to study data. JHH conducted statistical analysis and wrote the initial draft of the manuscript with oversight and support by ALW. All authors review and provided scientific input.

Funding This work was supported by funding from PEPFAR through the US Agency for International Development (Cooperative Agreement No AID-OAA-A-12-00058) to the Johns Hopkins Center for Communication Programs. This research has also been facilitated by the infrastructure and resources provided by the Johns Hopkins University Center for AIDS Research, an NIH-funded program (P30AI094189), which is supported by the following $\mathrm{NIH}$ cofunding and participating institutes and centres: NIAID, NCI, NICHD, NHLBI, NIDA, NIMH, NIA, FIC, NIGMS, NIDDK and OAR.

Disclaimer The findings and conclusions in this report are those of the authors and do not necessarily represent the official position of the US Government, USAID, PEPFAR, the NIH or any other affiliate organisations or institutions.

\section{Competing interests None declared.}

Patient consent for publication Not required.

Ethics approval The study was approved by the Johns Hopkins Bloomberg School of Public Health Institutional Review Board and the National Committee of Bioethics for Health (CNBS) in Mozambique.

Provenance and peer review Not commissioned; externally peer reviewed. Data availability statement Data are available upon reasonable request.

Open access This is an open access article distributed in accordance with the Creative Commons Attribution Non Commercial (CC BY-NC 4.0) license, which permits others to distribute, remix, adapt, build upon this work non-commercially, and license their derivative works on different terms, provided the original work is properly cited, appropriate credit is given, any changes made indicated, and the use is non-commercial. See: http://creativecommons.org/licenses/by-nc/4.0/.

\section{REFERENCES}

1. UNAIDS. 90-90-90 - An ambitious treatment target to help end the AIDS epidemic, 2014. Available: http://www.unaids.org/sites/default/ files/media_asset/90-90-90_en.pdf [Accessed 21 Apr 2018].

2. UNAIDS. Miles to go: closing gaps, breaking barriers, righting injustices, 2018. Available: http://www.unaids.org/sites/default/files/ media_asset/miles-to-go_en.pdf [Accessed 10 Jan 2019]. 
3. Higgins JA, Hoffman S, Dworkin SL. Rethinking gender, heterosexual men, and women's vulnerability to HIV/AIDS. Am J Public Health 2010;100:435-45.

4. Gunn JKL, Asaolu IO, Center KE, et al. Antenatal care and uptake of HIV testing among pregnant women in sub-Saharan Africa: a crosssectional study. J Int AIDS Soc 2016;19:20605.

5. Mills EJ, Beyrer C, Birungi J, et al. Engaging men in prevention and care for HIV/AIDS in Africa. PLoS Med 2012;9:e1001167.

6. Beckham SW, Beyrer C, Luckow P, et al. Marked sex differences in all-cause mortality on antiretroviral therapy in low- and middleincome countries: a systematic review and meta-analysis. J Int AIDS Soc 2016;19:21106

7. Chesney MA, Smith AW. Critical delays in HIV testing and care: the potential role of stigma. Am Behav Sci 1999;42:1162-74.

8. Katz IT, Ryu AE, Onuegbu AG, et al. Impact of HIV-related stigma on treatment adherence: systematic review and meta-synthesis. $J$ Int AIDS Soc 2013;16(3 Suppl 2):18640.

9. Meiberg AE, AER B, Onya HE, et al. Fear of stigmatization as barrier to voluntary HIV counselling and testing in South Africa. East Afri J Public Health 2008;5:49-54

10. Fortenberry JD, McFarlane M, Bleakley A, et al. Relationships of stigma and shame to gonorrhea and HIV screening. Am J Public Health 2002;92:378-81.

11. Gesesew HA, Tesfay Gebremedhin A, Demissie TD, et al. Significant association between perceived HIV related stigma and late presentation for HIV/AIDS care in low and middle-income countries: a systematic review and meta-analysis. PLoS One 2017;12:e0173928.

12. Rueda S, Mitra S, Chen S, et al. Examining the associations between HIV-related stigma and health outcomes in people living with HIV/AIDS: a series of meta-analyses. BMJ Open 2016;6:e011453.

13. Musheke M, Ntalasha $\mathrm{H}$, Gari $\mathrm{S}$, et al. A systematic review of qualitative findings on factors enabling and deterring uptake of HIV testing in sub-Saharan Africa. BMC Public Health 2013;13:220.

14. UNAIDS. Country factsheets: Mozambique 2016, 2017. Available: http://www.unaids.org/en/regionscountries/countries/mozambique [Accessed 16 Mar 2018].

15. The Demographic and Health Surveys (DHS) Program. DHS survey: 2018. Mozambique: standard AIS, 2015. Available: https:// dhsprogram.com/what-we-do/survey/survey-display-467.cfm [Accessed 16 Mar 2018].

16. Dokubo EK, Shiraishi RW, Young PW, et al. Awareness of HIV status, prevention knowledge and condom use among people living with HIV in Mozambique. PLoS One 2014;9:e106760.

17. Kujawski SA, Lamb MR, Lahuerta M, et al. Advanced human immunodeficiency virus disease at diagnosis in Mozambique and Swaziland. Open Forum Infect Dis 2017;4:ofx156.

18. Blevins M, José E, Bilhete FR, et al. Two-year death and loss to follow-up outcomes by source of referral to HIV care for HIV-infected patients initiating antiretroviral therapy in rural Mozambique. AIDS Res Hum Retroviruses 2015;31:198-207.
19. Yao J, Agadjanian V, Murray AT. Spatial and social inequities in HIV testing utilization in the context of rapid scale-up of HIV/AIDS services in rural Mozambique. Health Place 2014;28:133-41.

21. Global Network of People Living with HIV, International Planned Parenthood Federation, International Community of Women Living with HIV/AIDS, UNAIDS. The people living with HIV stigma index, Geneva 2008. Available: http://www.stigmaindex.org/ [Accessed 1 Jul 2018]

21. Carrasco MA, Arias R, Figueroa ME. The multidimensional nature of HIV stigma: evidence from Mozambique. Afr J AIDS Res 2017;16:11-18.

22. Genberg BL, Kawichai S, Chingono A, et al. Assessing HIV/AIDS stigma and discrimination in developing countries. AIDS Behav 2008;12:772-80.

23. The Demographic and Health Surveys (DHS) Program. Aids indicator survey (AIS), 201. Available: https://dhsprogram.com/What-We-Do/ Survey-Types/AIS.cfm [Accessed 16 Mar 2018].

24. StataCorp. Stata statistical software: release 14. College Station, TX StataCorp; 2015.

25. Jeffries WL, Townsend ES, Gelaude DJ, et al. HIV stigma experienced by young men who have sex with men (MSM) living with HIV infection. AIDS Educ Prev 2015;27:58-71.

27. Sherr K, Cuembelo F, Michel C, et al. Strengthening integrated primary health care in Sofala, Mozambique. BMC Health Serv Res 2013;13(Suppl 2):S4.

27. Audet CM, Chire YM, Vaz LME, et al. Barriers to male involvement in antenatal care in rural Mozambique. Qual Health Res 2016;26:1721-31.

28. Audet CM, Blevins M, Chire YM, et al. Engagement of men in antenatal care services: increased HIV testing and treatment uptake in a community participatory action program in Mozambique. AIDS Behav 2016;20:2090-100.

29. Hector J, Davies M-A, Dekker-Boersema J, et al. Acceptability and performance of a directly assisted oral HIV self-testing intervention in adolescents in rural Mozambique. PLoS One 2018;13:e0195391.

30. Figueroa ME, Poppe P, Carrasco M, et al. Effectiveness of community dialogue in changing gender and sexual norms for HIV prevention: evaluation of the Tchova Tchova program in Mozambique. J Health Commun 2016;21:554-63.

31. Myers M. Radio and development in Africa: a concept paper. International development research centre (IDRC), 2008. Available: http://www.amarc.org/documents/manuals/12481943581Radio and Development_in_Africa,_a_concept_paper.pdf [Accessed 1 Jul 2018].

32. Mall S, Middelkoop K, Mark D, et al. Changing patterns in HIV/AIDS stigma and uptake of voluntary counselling and testing services: the results of two consecutive community surveys conducted in the Western Cape, South Africa. AIDS Care 2013;25:194-201.

33. Hatzenbuehler ML, Phelan JC, Link BG. Stigma as a fundamental cause of population health inequalities. Am J Public Health 2013;103:813-21.

34. Mahajan AP, Sayles JN, Patel VA, et al. Stigma in the HIV/AIDS epidemic: a review of the literature and recommendations for the way forward. AIDS 2008;22(Suppl 2):S57-S65. 